\title{
Molecular surveillance and temporal monitoring of malaria parasites in focal Vietnamese provinces
}

\author{
Bui Van Long ${ }^{1}$, Genevieve Allen', Melanie Brauny ${ }^{1}$, Le Thi Kieu Linh ${ }^{1,2}$, Srinivas Reddy Pallerla', \\ Tran Thi Thu Huyen ${ }^{3}$, Hoang Van Tong ${ }^{3,4}$, Nguyen Linh Toan ${ }^{3}$, Do Quyet ${ }^{5}$, Ho Anh Son ${ }^{3 *}$ \\ and Thirumalaisamy P. Velavan ${ }^{1,2^{*}}$ (1)
}

\begin{abstract}
Background: While the World Health Organization (WHO) Southeast Asia region has the second highest incidence of malaria worldwide, malaria in Vietnam is focal to few provinces, where delayed parasite clearance to anti-malarial drugs is documented. This study aims to understand Plasmodium species distribution and the genetic diversity of msp1 and msp2 of parasite populations using molecular tools.

Methods: A total of 222 clinical isolates from individuals with uncomplicated malaria were subjected to Plasmodium species identification by nested real-time PCR. 166 isolates positive for Plasmodium falciparum mono infections were further genotyped for msp1 (MAD20, K1, and RO33), and msp2 allelic families (3D7 and FC27). Amplicons were resolved through capillary electrophoresis in the QIAxcel Advanced system.

Results: Mono-infections were high and with 75\% P. falciparum, 14\% Plasmodium vivax and 9\% P. falciparum/P. vivax co-infections, with less than 1\% Plasmodium malariae identified. For msp1, MAD20 was the most prevalent (99\%), followed by K1 (46\%) allelic family, with no sample testing positive for RO33 (0\%). For msp2, 3D7 allelic family was predominant (97\%), followed by FC27 (10\%). The multiplicity of infection of msp1 and msp2 was 2.6 and 1.1, respectively, and the mean overall multiplicity of infection was 3.7, with the total number of alleles ranging from 1 to 7 .

Conclusions: Given the increasing importance of antimalarial drugs in the region, the genetic diversity of P. falciparum msp1 and msp2 should be regularly monitored with respect to treatment outcomes and/or efficacy studies in regions, where there are ongoing changes in the malaria epidemiology.
\end{abstract}

Keywords: Malaria, Species, msp1, msp2, Multiplicity of infection, Vietnam

*Correspondence: hoanhsonhp@gmail.com; velavan@medizin. uni-tuebingen.de

${ }^{1}$ Institute of Tropical Medicine, Universitätsklinikum Tübingen, Wilhelmstrasse 27, 72074 Tübingen, Germany

${ }^{3}$ Institute of Biomedicine and Pharmacy, Vietnam Military Medical University, Hanoi, Vietnam

Full list of author information is available at the end of the article

\section{Background}

Malaria is still one of the overwhelming public health problems worldwide, and the World Health Organization (WHO) Southeast Asia region has the second highest incidence of malaria with a total of 7.9 million cases in 2018 [1]. Although there are encouraging reports of declined malaria morbidity and mortality in Vietnam since last two decades [2], malaria prevalence in central and southern provinces is still high, in particular provinces bordering Laos and Cambodia [3]. Although 40

(c) The Author(s) 2020. This article is licensed under a Creative Commons Attribution 4.0 International License, which permits use, sharing, adaptation, distribution and reproduction in any medium or format, as long as you give appropriate credit to the original author(s) and the source, provide a link to the Creative Commons licence, and indicate if changes were made. The images or other third party material in this article are included in the article's Creative Commons licence, unless indicated otherwise in a credit line to the material. If material is not included in the article's Creative Commons licence and your intended use is not permitted by statutory regulation or exceeds the permitted use, you will need to obtain permission directly from the copyright holder. To view a copy of this licence, visit http://creativecommons.org/licenses/by/4.0/. The Creative Commons Public Domain Dedication waiver (http//creativecommons.org/publicdomain/zero/1.0/) applies to the data made available in this article, unless otherwise stated in a credit line to the data. 
out of 63 provinces in Vietnam are declared malaria-free, only a few individual provinces contribute to a third of the cases in the country each year [3], with an additional 1600 imported cases contributing to the burden, a phenomenon first reported in 2018 [1].

In Vietnam, Plasmodium falciparum (64\%) and Plasmodium vivax (35\%) are the most important malaria parasites. Artemisinin-based combination therapy (ACT), especially using dihydroartemisinin piperaquine (DHAPPQ), is the first-line of treatment [1]. One of the main obstacles to malaria control is the parasites' ability to develop artemisinin resistance [4], which is inherently defined as delayed parasite clearance [5,6]. Resistance to artemisinin is well documented in Vietnam, Western Cambodia and Thai-Myanmar borders [7]. Since a significant proportion of the Vietnamese population lives in malaria endemic areas, where resistant phenotypes have been reported, studies to decipher the genetic diversity and multiplicity of infections (MOI) of $P$. falciparum are essential to understand the intensity of transmission, epidemiological patterns and virulence of the parasites and, in particular, to evaluate measures aimed at malaria control [8-11].

The diversity of $P$. falciparum is usually determined by the evaluation of the extent of the polymorphism of the merozoite surface proteins $m s p 1$ and $m s p 2$, which are expressed on the surface of the merozoites during the erythrocytic stage of the life cycle of $P$. falciparum $[12,13]$. The $m s p 1$ gene on chromosome 9 consists of 17 different blocks, and block 2 is highly polymorphic and consists of three different allelic families: MAD20, $\mathrm{K} 1$ and RO33. The msp 2 gene on chromosome 2 contains highly polymorphic central repeats in block 3 and is distinguishable for two allelic families: 3D7 and FC27. Both $m s p 1$ and $m s p 2$ are highly immunogenic and are considered potential blood stage vaccine candidates [14, 15]. These two genetic markers are often used to indicate the number of parasitic strains present in a single host, which is useful in distinguishing between recrudescence and reinfection in drug efficacy studies [16]. The clonality of infection is the number of distinct clones/strain/ genotypes per isolate (infected individual). More than one clone/genotype therefore implies polyclonality. Consequently, the mean number of genotypes or clones per infected individual (isolate) is defined to be the "multiplicity of infection" (MOI). A high MOI indicates that a single host carries multiple parasite strains and is associated with drug resistance of $P$. falciparum with excessive parasite transmission in holoendemic areas [16] .

In Vietnam, the predominant $m s p 1$ and $m s p 2$ alleles in 2012 [17] are MAD20 [18] and 3D7 [19], respectively. This study aims to determine the distribution of the Plasmodium species and subsequently the different $m s p 1, m s p 2$ genotypes and to estimate the MOI in clinical isolates from malaria endemic areas in Vietnam.

\section{Methods \\ Study area and sampling}

Written informed consent was obtained from all study participants. The study was approved by the Institutional Review Board of Vietnam Military Medical University, Hanoi, Vietnam. The study included 222 clinical isolates collected from adult individuals with uncomplicated malaria (mean age $=29.1 \pm 9.5 ; 88 \%$ female). An individual who presents with symptoms of malaria and a positive parasitological test (microscopy or RDT) but with no features of severe malaria is defined as having uncomplicated malaria. Clinical isolates were collected in Vietnamese provinces, which included Dak Lak, Gia Lai and Dak Nong between years 2017-2019. The three provinces (Dak Lak, Gia Lai and Dak Nong) are adjacent to each other and are part of the central highlands bordering Cambodia. Whole blood samples were collected from individuals and were microscopically confirmed for the presence of Plasmodium parasites. Blood samples were stored at $-20^{\circ} \mathrm{C}$ until further use.

\section{Plasmodium species identification using nested real-time PCR}

Genomic DNA was isolated from $50 \mu \mathrm{l}$ whole blood using the QIAamp DNA Mini-Kit (Qiagen, Hilden, Germany) according to the manufacturer's protocol. For detection and characterization of the Plasmodium species, a Taqman probe-based Pan-Plasmodium realtime PCR was used, as described earlier [20].

In short, the parasite DNA was amplified in a conventional PCR using the primers PLU5 and PLU6 [21]. The amplicons from the above PCR were used as templates in a single-plex nested real-time PCR assay for the differentiation of Plasmodium species. In each single-plex nested real-time PCR assay, distinct primers for P. falciparum [22], P. vivax [23], Plasmodium malariae, Plasmodium ovale curtisi, Plasmodium ovale wallikeri [20] are specifically used (Table 1 ). The assays were performed using SensiFAST ${ }^{\mathrm{TM}}$ Probe No-ROX Kit (Bioline, Tennessee, USA) in a LightCycler 480 Instrument II (Roche, Basel, Switzerland). Each clinical isolate was run in duplicates. The success of amplification is defined by respective $\mathrm{Ct}$ values that are smaller or equal to 40. All assays included a non-template control and positive control. The $\mathrm{Ct}$ values were calculated by default using the second derivative maximum method integrated in the LightCycler 480 software (version 1.5.1.62). 
Table 1 List of primers used for plasmodium species identification using nested real-time PCR

\begin{tabular}{|c|c|c|c|c|c|c|}
\hline Genus/species & Target & Primer ID & Primer sequence $\left(5^{\prime}-3^{\prime}\right)$ & $5^{\prime}$ modified & $3^{\prime}$ modified & References \\
\hline \multirow[t]{2}{*}{ Plasmodium } & 18S rRNA gene & rPLU6-F & TTAAAATTGTTGCAGTTAAAACG & & & {$[21]$} \\
\hline & & rPLU5-R & CCTGTTGTTGCCTTAAACTTC & & & \\
\hline \multirow[t]{3}{*}{ P. falciparum } & 18S rRNA type $S$ & PF-F & ATTGCTTTTGAGAGGTTTTGTTACTTT & & & {$[22]$} \\
\hline & & PF-R & GCTGTAGTATTCAAACACAATGAACTCAA & & & \\
\hline & & PF-Probe & CATAACAGACGGGTAGTCAT & HEX & MGBEQ & \\
\hline \multirow[t]{3}{*}{ P. vivax } & 18S rRNA type A & VIV-F & GCAACGCTTCTAGCTTAATCCAC & & & {$[23]$} \\
\hline & & VIV-R & CAAGCCGAAGCAAAGAAAGTCC & & & \\
\hline & & VIV-Probe & ACTTTGTGCGCATTTTGCTA & HEX & MGBEQ & \\
\hline \multirow[t]{3}{*}{ P. malariae } & 18S rRNA gene & PM-F & GGTGTTGGATGATAGAGTAA & & & {$[20]$} \\
\hline & & PM-R & CCCAAAGACTTTGGATTTCTC & & & \\
\hline & & PM-Probe & AGGAAGCTATCTAAAAGAAACACTCAT & HEX & $\mathrm{BHQ}-1$ & \\
\hline \multirow[t]{3}{*}{ P. ovale curtisi } & 18S rRNA gene & POS-F & ATTTCAAAGAGTCATGGCGTTTCTG & & & {$[20]$} \\
\hline & & POS-R & TTGTAAAGGAGACACTTTCTTGAAATCG & & & \\
\hline & & POS-Probe & CTCCTTGGTCGATCTGCCCAGCACT & FAM & $\mathrm{BHQ}-1$ & {$[20]$} \\
\hline \multirow[t]{3}{*}{ P. ovale wallikeri } & 18S rRNA gene & POS-F & ATTTCAAAGAGTCATGGCGTTTCTG & & & \\
\hline & & POW-R & TGTAAAGGAGACAACTTTCTTGGAGCTA & & & \\
\hline & & POW-Probe & TTGATCGCCCAGCACTGACCATCT & HEX & $\mathrm{BHQ}-1$ & \\
\hline
\end{tabular}

HEX: 6-hexachlorofluorescein; FAM: 6-carboxyfluorescein; MGBEQ: minor groove binder eclipse quencher. BHQ-1: black hole quencher-1. rRNA: ribosomal ribonucleic acid

\section{Plasmodium falciparum msp1 and msp2 genotyping}

The samples positive for $P$. falciparum were genotyped by nested PCR. The outer PCR was used to amplify conserved regions of $m s p 1$ and $m s p 2$ and then the nested PCR was used to amplify MAD20, K1 and RO33 allele families at the msp1 gene locus and 3D7 and FC27 allele families at the $m s p 2$ gene locus. The outer and inner PCRs were performed with published primers as described elsewhere [24].

In brief: for the outer PCR, the DNA fragment was amplified in a reaction mixture of $20 \mu \mathrm{l}$ volume containing 1x PCR buffer (20 mM Tris- $\mathrm{HCl} \mathrm{pH} \mathrm{8.4,} 50 \mathrm{mM}$ $\mathrm{KCl}, 1.5 \mathrm{mM} \mathrm{MgCl}_{2}$ ), $200 \mu \mathrm{M}$ dNTPs, $100 \mathrm{nM}$ of each primer and $1 \mathrm{U}$ Taq DNA polymerase (Qiagen, Hilden, Germany) on an Eppendorf Nexus Gradient PCR Cycler (Eppendorf, Hamburg, Germany). The thermal cycle parameters for the first PCR amplification were: initial denaturation at $94{ }^{\circ} \mathrm{C}$ for $10 \mathrm{~min}$, followed by 35 cycles of $30 \mathrm{~s}$ at $94{ }^{\circ} \mathrm{C}$ denaturation, $30 \mathrm{~s}$ at $55^{\circ} \mathrm{C}$ annealing, $1 \mathrm{~min}$ at $72{ }^{\circ} \mathrm{C}$ extension, followed by a final extension of $10 \mathrm{~min}$ at $72{ }^{\circ} \mathrm{C}$. The inner PCRs for the allele families MAD20, K1 and RO33 (msp1) and 3D7 and FC27 $(m s p 2)$ were performed with the outer PCR templates of $m s p 1$ and $m s p 2$, respectively. All five reactions were performed independently in $25 \mu \mathrm{l}$ reaction mixture containing $3 \mu \mathrm{l}$ from the outer PCR template, 1x PCR buffer, $1 U$ Taq polymerase (Qiagen, Hilden, Germany), $200 \mu \mathrm{M}$ dNTPs, $100 \mathrm{nM}$ forward and reverse primers (Eurofins Genomic, Ebersberg, Germany). The PCR reaction conditions are identical to those of the outer PCR, except that the annealing temperature was $61{ }^{\circ} \mathrm{C}$ for the $m s p 1$ allele families and $56{ }^{\circ} \mathrm{C}$ for the $m s p 2$ allele families. For the $m s p 1$ positive controls, $P$. falciparum DNA was isolated from the strains Dd2, NF54 and 7G8 for the alleles MAD20, K1 and RO33, respectively. For the $m s p 2$ positive controls, DNA was isolated from $P$. falciparum strains Dd2 and NF54 for alleles 3D7 and FC27, respectively.

The QIAxcel Advanced system (Qiagen, Hilden, Germany) was used to resolve the amplicons by capillary electrophoresis. All nested PCR products were performed according to the AM420 protocol using the QX-DNA size marker 50-800 bp (Qiagen, Hilden, Germany) and the QX alignment marker $15 \mathrm{bp} / 1 \mathrm{~kb}$ (Qiagen, Hilden, Germany), except for the nested PCR products of the $m s p 1$ allele family $\mathrm{K} 1$. The nested $\mathrm{K} 1$ PCR products were performed using the AM420 protocol with the QX DNA size marker $100 \mathrm{bp}-2.5 \mathrm{~kb}$ (Qiagen, Hilden, Germany) and the QX alignment marker 15 bp/3 kb (Qiagen, Hilden, Germany).

The results were analysed with the QIAxcel Screen Gel software (Version 1.5.0.16, Qiagen, Hilden, Germany). All positive controls yielded a single peak, except the FC27 positive control, which clearly showed two peaks in each run (MAD20: 201, K1: 242 bp, RO33: 154 bp, 3D7: 237 bp, FC27: 469/623 bp). Each band represents one allele in the respective allele families (Fig. 1). 


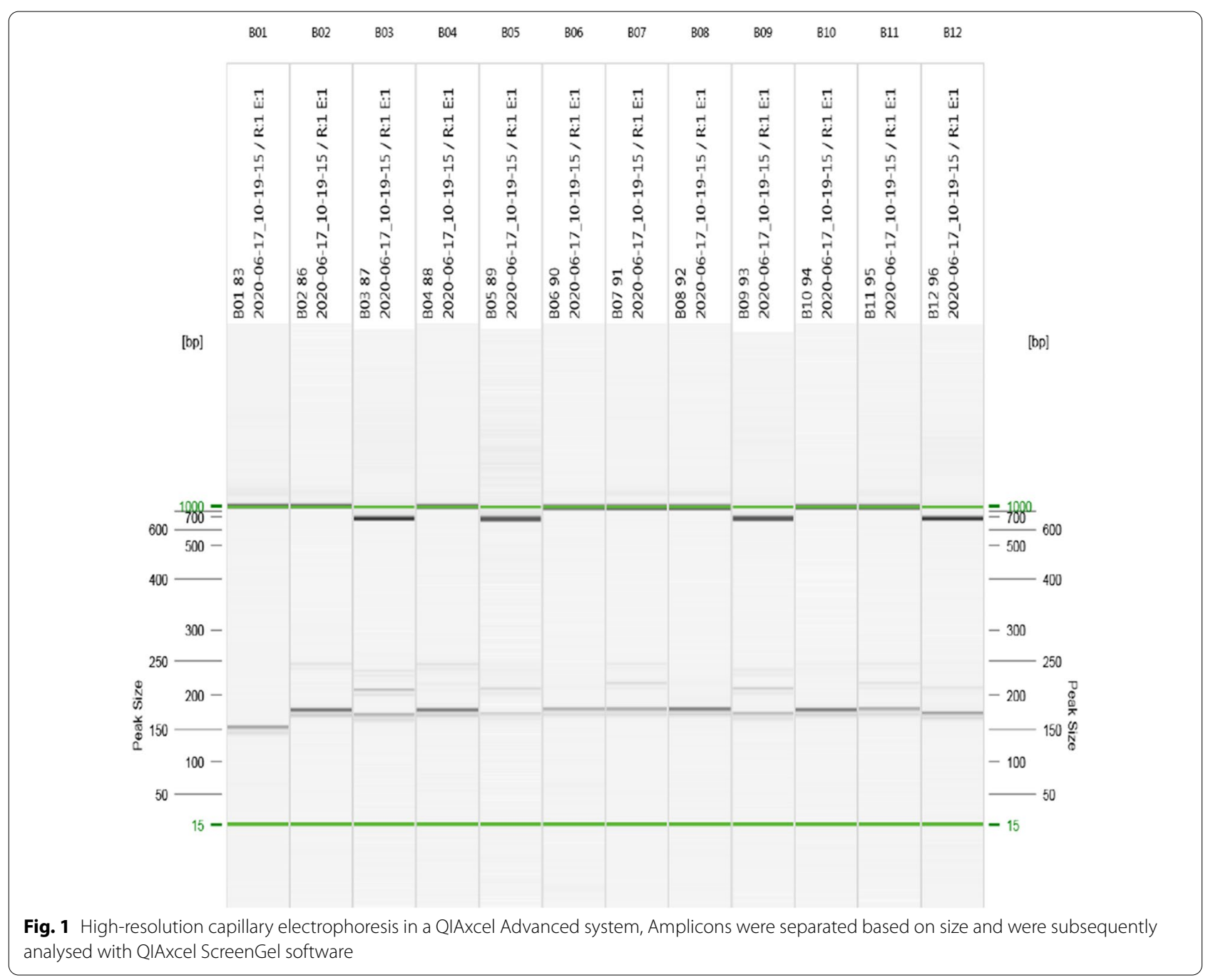

\section{Multiplicity of infection (MOI)}

The MOI was defined as the mean number of $P$. falciparum genotypes per infected individual. The MOI was calculated as a proportion of the total number of P. falciparum msp 1 and $m s p 2$ genotypes and the total number of PCR positive isolates. Isolates with only one allele at each locus were considered single infections. Infections with more than one allele at one or more loci were considered polyclonal infections.

\section{Results}

\section{Plasmodium species identification}

On screening 222 samples, 166 (75\%) isolates were positive for $P$. falciparum, 32 (14\%) isolates were positive for $P$. vivax, one isolate was positive for P. malariae and 20 (9\%) isolates were positive for both $P$. falciparum and $P$. vivax, indicating co-infection. Furthermore, we did not find any isolates positive for $P$. ovale curtisi and $P$. ovale wallikeri. In total, 3 (2\%) of the isolates were PCR negative.

\section{Genetic diversity and allelic frequency}

All 166 isolates positive for P. falciparum by nested realtime PCR were subsequently genotyped for both $m s p 1$ and $m s p 2$ loci (Table 2). A total of 160 isolates were successfully amplified for $m s p 1$ and 153 isolates for $m s p 2$ loci, respectively. The MAD20 allelic family was predominant in 159 (99\%) followed by K1 74 (46\%) isolates, with the complete absence of RO33 allelic family. In msp1, $85(53 \%)$ isolates were positive for MAD20 only and 73 (46\%) isolates were positive for both MAD20 and K1, except one $(0.6 \%)$ isolate that was positive for K1 only. In the $m s p 2$ locus the 3D7 allele family was predominant in 148 (97\%) and the FC27 allele family in $16(10 \%)$ isolates. A total of 137 (90\%) isolates were positive for 3D7 and $11(7 \%)$ positive for both 3D7 and FC27. There were up to 7 different alleles for $m s p 1$, with allele sizes varying 
Table 2 Distribution of $m s p 1$ and $m s p 2$ alleles

\begin{tabular}{ll}
\hline Alleles & Positive N (\%) \\
\hline msp1 ( $\mathrm{n}=160)$ & \\
MAD20 allelic family & $159(99 \%)$ \\
K1 allelic family & $74(46 \%)$ \\
RO33 allelic family & $0(0 \%)$ \\
MAD20 + K1 (polyclonal) & $73(46 \%)$ \\
MAD 20 (monoclonal) & $85(53 \%)$ \\
K1 (monoclonal) & $1(0.6 \%)$ \\
Mean MOl msp1 ( \pm SD) & $2.6 \pm 1$ \\
msp2 ( $=153$ ) & \\
3D7 allelic family & $148(97 \%)$ \\
FC27 allelic family & $16(10 \%)$ \\
3D7+ FC27 (polyclonal) & $11(7 \%)$ \\
3D7 (monoclonal) & $137(90 \%)$ \\
FC27 (monoclonal) & $5(3 \%)$ \\
Mean MOl msp2 ( \pm SD) & $1.1 \pm 0.5$ \\
Overall MOI (msp1 + msp2) & $3.7 \pm 1.2$ \\
\hline
\end{tabular}

between 141 and 255 bp (MAD20) and 161-1270 bp (K1). There were up to 4 different alleles for $m s p 2$, with allele sizes varying between 248 and $650 \mathrm{bp}$ (3D7) and 366-531 bp (FC27).

\section{Multiplicity of infection (MOI)}

Multiplicity of infection was calculated from the msp1 and $m s p 2$ genotyping results. A mean MOI of $2.6 \pm 1$ for $m s p 1$ and a mean MOI of $1.1 \pm 0.5$ for $m s p 2$, and an overall MOI for $m s p 1$ and $m s p 2$ is $3.7 \pm 1.2$ observed. There is no significant distribution of MOI between age groups.

\section{Discussion}

In this study, 222 clinical isolates were tested for Plasmodium species using sensitive real-time nested qPCR and were characterized the P. falciparum diversity, and MOI using molecular epidemiological tools.

From the nested real-time PCR results, 75\% P. falciparum was observed, followed by $15 \%$ P. vivax and $8 \%$ $P$. falciparum/P. vivax co-infections. These results differ slightly from those of the WHO, where $64 \%$ was reported for $P$. falciparum and $35 \%$ for P. vivax in Vietnam [25]. These differences may be due to the fact that this study used a highly sensitive real-time PCR-based assay that is sensitive enough to detect submicroscopic infections. Another study showed that monitoring between December 2013 and January 2016 revealed 36\% P. falciparum, $27 \%$ P. vivax, 25\% co-infections with $P$. falciparum and $P$. vivax and $12 \%$ unidentified species from the same region [26]. In addition, it was reported that between 2006 and 2010, $70 \%$ of infections in Vietnam were due to P. falciparum. However, due to control measures, there has been a stronger impact on $P$. falciparum than on $P$. vivax since 2014, resulting in an almost equal ratio of both species [27]. Furthermore, co-infections with P. knowlesi and $P$. vivax have been documented in mosquitoes and humans in South Vietnam [28].

The use of ACT may have population-wide benefits in malaria control due to their effect in reducing the transfer of gametocytes, the sexual stage of the parasite, transmitted from humans to an Anopheles mosquito, during a blood meal [29, 30]. Rapid killing of the asexual parasite stages with artemisinin (99\% daily killing rate) [29, 30] and, in combination with a partner drug, leads to a microscopically undetectable parasitaemia after 3 days of treatment [31]. Despite the decline of P. falciparum malaria in the last 10 years, and ACT being introduced as a component of comprehensive malaria control efforts, it is a challenge to reduce $P$. falciparum malaria cases in these provinces. The fact that the use of indoor spraying and insecticide-treated mosquito nets (ITN) is equally to contribute to these changes in the malaria epidemiology. Studies of the therapeutic efficacy of first-line treatment with DHA-PPQ at national sentinel sites have shown delayed parasite clearance in Gia Lai Province (2010), Dak Nong Province (2011), Quang Nam Province (2012), Khanh Hoa Province (2014) and Ninh Thuan Province (2015), with over $10 \%$ of patients being microscopically positive on day 3 after treatment initiation [32, 33].

Given the increasing importance of antimalarial drugs in the region, the genetic diversity of $P$. falciparum $m s p 1$ and $m s p 2$ should be regularly monitored with respect to treatment outcomes and/or efficacy studies in regions, where there are ongoing changes in the malaria epidemiology, as mentioned above [8,9]. When magnified to understand the extent of parasite diversity in these provinces, the msp1 MAD20 allelic family (99\%) and the msp2 3D7 allelic family was predominant (97\%). These results are in accordance with an earlier study from Vietnam [17]. Another longitudinal study in the region, in Myanmar between 2004 and 2006 and 2013-2015 shows changes in the $m s p 1$ and $m s p 2$ allele distribution over time [19]. For example, the RO33 prevalence changed from 0\% (2004-2006) to 21\% (2013-2015). The RO33 allele appears to occur in low frequency in this geographical region, as also in Myanmar where the presence of this type in parasites is also rare [34, 35]. Nevertheless, MAD20 and 3D7 remained predominant for almost two decades [19].

Studies with multiplicity of infections (MOI) are rare in Vietnam. The overall MOI of $m s p 1$ and $m s p 2$ in this study was 2.6 and 1.1, respectively, and these differ from those in Thailand and Laos, which are geographically closer to Vietnam. For $m s p 1$, the MOI in Thailand and Laos are 1.7 and 1.6, respectively, and for $m s p 2$, the 
MOI in Thailand is 2.5 [36, 37]. These differences may be due to differences in transmission intensity, population and geographical areas. The investigations were performed with a QIAxcel Advanced system, compared to previously reported investigations performed with conventional slab gel electrophoresis. This automated sensitive, high-resolution capillary electrophoresis performed DNA fragment analysis with the QIAxcel ScreenGel software with a power to discriminate alleles with a 3-5 bp resolution.

Against the background of the increasing importance of resistance to antimalarial drugs, which is reported in the region, a low to moderate genetic diversity was observed in the focal endemic provinces in Vietnam based on the genetic diversity of $P$. falciparum msp 1 and $m s p 2$. Routine monitoring of parasite genetic diversity has important implications for linking treatment outcomes and/or efficacy studies as the epidemiology of malaria changes.

\section{Acknowledgements}

The authors acknowledge the technical support from Mrs. Jutta Kun for the use of QIAExcel instrumentation.

\section{Authors' contributions}

TPV designed, supervised the study and contributed to the materials and wrote the manuscript. BVL and GA performed the experimental procedures for msp1 and 2 genotyping, MB, LTKL, SRP performed the experimental procedures on species identification. TTTH, HVT, NLT, DQ were involved in the study design and coordination with clinical research team. HAS recruited the patients and is the PI for this clinical study. All authors agreed with the results and conclusions. All authors read and approved the final manuscript.

\section{Funding}

Open Access funding enabled and organized by Projekt DEAL. The author TPV acknowledges the German Academic Exchange Service (DAAD) (57445019) for student fellowships and also the German Federal Ministry of Education and Research (BMBF01DP17047: Vietnamese German Center for Excellence).

\section{Availability of data and materials}

All related material and data are included in this manuscript.

\section{Ethics approval and consent to participate}

Informed written consent was obtained from all study participants. The study was approved by the Institutional Review Board of Vietnam Military Medical University, Hanoi, Vietnam.

\section{Consent for publication}

All authors have read and approved this submission. All authors have consented to publish this as an original article.

\section{Competing interests}

All authors disclose no competing interests.

\footnotetext{
Author details

1 Institute of Tropical Medicine, Universitätsklinikum Tübingen, Wilhelmstrasse 27, 72074 Tübingen, Germany. ${ }^{2}$ Vietnamese-German Centre for Medical Research (VG-CARE), Hanoi, Vietnam. ${ }^{3}$ Institute of Biomedicine and Pharmacy, Vietnam Military Medical University, Hanoi, Vietnam. ${ }^{4}$ Department of Pathophysiology, Vietnam Military Medical University, Hanoi, Vietnam. ${ }^{5}$ Vietnam Military Medical University, Hanoi, Vietnam.
}

Received: 19 October 2020 Revised: 18 December 2020 Accepted: 18 December 2020

Published online: 31 December 2020

\section{References}

1. WHO. World malaria report 2019. Geneva: World Health Organization; 2019.

2. Goldlust $\mathrm{SM}$, Thuan PD, Giang DDH, Thang ND, Thwaites GE, Farrar J, et al. The decline of malaria in Vietnam, 1991-2014. Malar J. 2018;17:226.

3. Phuong NL. Viet Nam ready to eliminate malaria. Geneva: World Health Organization; 2018.

4. Velavan TP, Nderu D, Agbenyega T, Ntoumi F, Kremsner PG. An alternative dogma on reduced artemisinin susceptibility: a new shadow from east to west. Proc Natl Acad Sci USA. 2019;116:12611-2.

5. Kremsner PG, Adegnika AA, Hounkpatin AB, Zinsou JF, Taylor TE, Chimalizeni $Y$, et al. Intramuscular artesunate for severe malaria in African children: a multicenter randomized controlled trial. PLoS Med. 2016;13:e1001938.

6. Krishna S, Staines HM, Kremsner PG. Artemisinin resistance and the blame game. Clin Infect Dis. 2016;63:1144-5.

7. Nguetse CN, Adegnika AA, Agbenyega T, Ogutu BR, Krishna S, Kremsner PG, et al. Molecular markers of anti-malarial drug resistance in Central, West and East African children with severe malaria. Malar J. 2017;16:217.

8. Zhong D, Lo E, Wang X, Yewhalaw D, Zhou G, Atieli HE, et al. Multiplicity and molecular epidemiology of Plasmodium vivax and Plasmodium falciparum infections in East Africa. Malar J. 2018;17:185.

9. Some AF, Bazie T, Zongo I, Yerbanga RS, Nikiema F, Neya C, et al. Plasmodium falciparum msp1 and msp2 genetic diversity and allele frequencies in parasites isolated from symptomatic malaria patients in Bobo-Dioulasso, Burkina Faso. Parasit Vectors. 2018;11:323.

10. Mahdi Abdel Hamid M, Elamin AF, Albsheer MM, Abdalla AA, Mahgoub NS, Mustafa SO, et al. Multiplicity of infection and genetic diversity of Plasmodium falciparum isolates from patients with uncomplicated and severe malaria in Gezira State, Sudan. Parasit Vectors. 2016;9:362.

11. Nguetse CN, Ojo JA, Nchotebah C, Ikegbunam MN, Meyer CG, Thomas BN, et al. Genetic diversity of the Plasmodium falciparum glutamaterich protein $\mathrm{r} 2$ region before and twelve years after introduction of artemisinin combination therapies among febrile children in Nigeria. Am J Trop Med Hyg. 2018;98:667-76.

12. Takala SL, Escalante AA, Branch OH, Kariuki S, Biswas S, Chaiyaroj SC, et al. Genetic diversity in the Block 2 region of the merozoite surface protein 1 (MSP-1) of Plasmodium falciparum: additional complexity and selection and convergence in fragment size polymorphism. Infect Genet Evol. 2006;6:417-24.

13. Apinjoh TO, Tata RB, Anchang-Kimbi JK, Chi HF, Fon EM, Mugri RN, et al. Plasmodium falciparum merozoite surface protein 1 block 2 gene polymorphism in field isolates along the slope of mount Cameroon: a cross - sectional study. BMC Infect Dis. 2015;15:309.

14. Genton B, Betuela I, Felger I, Al-Yaman F, Anders RF, Saul A, Rare L, et al. A recombinant blood-stage malaria vaccine reduces Plasmodium falciparum density and exerts selective pressure on parasite populations in a phase 1-2b trial in Papua New Guinea. J Infect Dis. 2002;185:820-7.

15. McCarthy JS, Marjason J, Elliott S, Fahey P, Bang G, Malkin E, et al. A phase 1 trial of MSP2-C1, a blood-stage malaria vaccine containing 2 isoforms of MSP2 formulated with Montanide(R) ISA 720. PLoS One. $2011 ; 6:$ e24413.

16. Mombo-Ngoma G, Remppis J, Sievers M, Zoleko Manego R, Endamne L, et al. Efficacy and safety of fosmidomycin-piperaquine as nonartemisininbased combination therapy for uncomplicated falciparum malaria: a single-arm, age de-escalation proof-of-concept study in Gabon. Clin Infect Dis. 2018;66:1823-30.

17. Aspeling-Jones H, Conway DJ. An expanded global inventory of allelic variation in the most extremely polymorphic region of Plasmodium falciparum merozoite surface protein 1 provided by short read sequence data. Malar J. 2018;17:345 
18. Ferreira MU, Liu Q, Zhou M, Kimura M, Kaneko O, Van Thien H, et al. Stable patterns of allelic diversity at themerozoite surface protein-1 locus of Plasmodium falciparum in clinical isolates from southern Vietnam. J Eukaryot Microbiol. 1998;45:131-6.

19. Le HG, Kang JM, Jun H, Lee J, Thai TL, Myint MK, et al. Changing pattern of the genetic diversities of Plasmodium falciparum merozoite surface protein-1 and merozoite surface protein-2 in Myanmar isolates. Malar J. 2019;8:241.

20. Groger M, Veletzky L, Lalremruata A, Cattaneo C, Mischlinger J, ZolekoManego R, et al. Prospective clinical trial assessing species-specific efficacy of artemether-lumefantrine for the treatment of Plasmodium malariae, Plasmodium ovale, and mixed Plasmodium malaria in Gabon. Antimicrob Agents Chemother. 2018;62:e01758-17.

21. Snounou G, Viriyakosol S, Zhu XP, Jarra W, Pinheiro L, do Rosario VE, et al. High sensitivity of detection of human malaria parasites by the use of nested polymerase chain reaction. Mol Biochem Parasitol. 1993;61:315-20.

22. Veron V, Legrand E, Yrinesi J, Volney B, Simon S, Carme B. Genetic diversity of msp3alpha and msp1_b5 markers of Plasmodium vivax in French Guiana. Malar J. 2009:8:40.

23. Kamau E, Alemayehu S, Feghali KC, Saunders D, Ockenhouse CF. Multiplex qPCR for detection and absolute quantification of malaria. PLOS ONE. 2013;8:e71539.

24. Atroosh WM, Al-Mekhlafi HM, Mahdy MA, Saif-Ali R, Al-Mekhlafi AM, Surin J. Genetic diversity of Plasmodium falciparum isolates from Pahang, Malaysia based on MSP-1 and MSP-2 genes. Parasit Vectors. 2011;4:233.

25. WHO. Malaria Country Profiles Viet Nam. Geneva: World Health Organization; 2018.

26. Nguyen TN, von Seidlein L, Nguyen TV, Truong PN, Hung SD, Pham HT, et al. The persistence and oscillations of submicroscopic Plasmodium falciparum and Plasmodium vivax infections over time in Vietnam: an open cohort study. Lancet Infect Dis. 2018;18:565-72.

27. Kattenberg $\mathrm{JH}$, Erhart $\mathrm{A}$, Truong MH, Rovira-Vallbona E, Vu KAD, Nguyen THN, et al. Characterization of Plasmodium falciparum and Plasmodium vivax recent exposure in an area of significantly decreased transmission intensity in Central Vietnam. Malar J. 2018;17:180.

28. Marchand RP, Culleton R, Maeno Y, Quang NT, Nakazawa S. Co-infections of Plasmodium knowlesi, P. falciparum, and P. vivax among humans and Anopheles dirus mosquitoes, Southern Vietnam. Emerg Infect Dis. 2011;17:1232-9.
29. Targett G, Drakeley C, Jawara M, von Seidlein L, Coleman R, Deen J, et al. Artesunate reduces but does not prevent posttreatment transmission of Plasmodium falciparum to Anopheles gambiae. J Infect Dis. 2001;183:1254-9.

30. Bousema JT, Schneider P, Gouagna LC, Drakeley CJ, Tostmann A, Houben $\mathrm{R}$, et al. Moderate effect of artemisinin-based combination therapy on transmission of Plasmodium falciparum. J Infect Dis. 2006;193:1151-9.

31. White NJ. Qinghaosu (artemisinin): the price of success. Science. 2008;320:330-4.

32. Phong NC, Chavchich M, Quang HH, San NN, Birrell GW, Chuang I, et al. Susceptibility of Plasmodium falciparum to artemisinins and Plasmodium vivax to chloroquine in Phuoc Chien Commune, Ninh Thuan Province, south-central Vietnam. Malar J. 2019;18:10.

33. Thanh NV, Thuy-Nhien N, Tuyen NT, Tong NT, Nha-Ca NT, Dong LT, et al. Rapid decline in the susceptibility of Plasmodium falciparum to dihydroartemisinin-piperaquine in the south of Vietnam. Malar J. 2017;16:27.

34. Kang JM, Moon SU, Kim JY, Cho SH, Lin K, Sohn WM, et al. Genetic polymorphism of merozoite surface protein-1 and merozoite surface protein-2 in Plasmodium falciparum field isolates from Myanmar. Malar J. 2010;9:131.

35. Soe TN, Wu Y, Tun MW, Xu X, Hu Y, Ruan Y, et al. Genetic diversity of Plasmodium falciparum populations in southeast and western Myanmar. Parasit Vectors. 2017;10:322.

36. Snounou G, Zhu X, Siripoon N, Jarra W, Thaithong S, Brown KN, et al. Biased distribution of msp1 and msp2 allelic variants in Plasmodium falciparum populations in Thailand. Trans R Soc Trop Med Hyg. 1999;93:369-74.

37. Khaminsou N, Kritpetcharat O, Daduang J, Charerntanyarak L, Kritpetcharat P. Genetic analysis of the merozoite surface protein-1 block 2 allelic types in Plasmodium falciparum clinical isolates from Lao PDR. Malar J. $2011 ; 10: 371$.

\section{Publisher's Note}

Springer Nature remains neutral with regard to jurisdictional claims in published maps and institutional affiliations.

Ready to submit your research? Choose BMC and benefit from:

- fast, convenient online submission

- thorough peer review by experienced researchers in your field

- rapid publication on acceptance

- support for research data, including large and complex data types

- gold Open Access which fosters wider collaboration and increased citations

- maximum visibility for your research: over $100 \mathrm{M}$ website views per year

At BMC, research is always in progress.

Learn more biomedcentral.com/submissions 